$67.32 \pm 0.17 \%$ for 90 -min until $3.08 \pm 0.04 \%(1.83 \pm 0.10 \mathrm{~kg})$ of their body weight loss. After which, the subjects move to the thermo neutral environment $\left(21.2 \pm 0.3^{\circ} \mathrm{C}\right)$ and seated for 30 min prior to begin the $2-h \mathrm{R}$ period. During $\mathrm{R}$, subjects drank either SD or PW representing $120 \%$ of the fluid lost divided in three boluses representation 50\% (915 $\pm 54 \mathrm{ml}), 40 \%(732 \pm 37$ $\mathrm{ml})$ and $30 \%(556 \pm 35 \mathrm{ml})$ at $0,30,60 \mathrm{~min}$, respectively. In the entire trials subjects were somewhat hypo hydrated (range $0.32-0.52 \mathrm{~kg}$ below initial body weight) after completing the $2-\mathrm{h} \mathrm{R}$ period. The percent body weight loss that was regained (used as index of percent rehydration) during SD and $\mathrm{PW}$ was $68 \pm 2 \%$ and $58 \pm 2 \%$, respectively, with significantly $(p<0.05)$ better $\mathrm{R}$ with SD compared with PW. The rehydration index for $\mathrm{SD}$ was significantly lower than PW $(p<0.01)$. PV was restored similarly to euhydration levels after 2 -h of $\mathrm{R}$ with SD but was significantly lower $(\mathrm{p}<0.05)$ with PW trials. Cumulative urine output was significantly higher for PW when compare to SD $(p<0.05)$. Serum $\mathrm{Cl}, \mathrm{Na}$ and $\mathrm{K}$ were significantly higher with $\mathrm{SD}(\mathrm{p}<0.05)$ and urine osmolality of PW trial were significantly lower $(p<0.05)$ than $\mathrm{SD}$ at the end of $2-\mathrm{h} \mathrm{R}$ period. Plasma glucose concentration were significantly higher when SD was ingested compared to PW $(p<0.01)$. In conclusion, ingesting the volume of $120 \%$ of losses still under hypohydrated because of urine production and SD was better than PW for rehydration after exerciseinduced dehydration.

\section{PERCENTAGE OF VOLUME INTAKE FOR REHYDRATION AFTER EXERCISE-INDUCED DEHYDRATION}

Ishak Ismail, ${ }^{1}$ Rabindarjeet Singh ${ }^{2}$ Department of Physical Education and Health, Teachers Education Institute, Sultan Mizan Campus, Kota Putera, Terengganu, Malaysia; ${ }^{2}$ Advance Medical and Dental Institute, USM, Penang, Malaysia

\subsection{6/bjsm.2010.078725.136}

The present cross over study assessed the percentage of dehydration and effectiveness of $120 \%$ rehydration (R) with sports drink (SD) and plain water (PW) on whole body rehydration (R), plasma volume (PV) restoration after exercise-induced dehydration. Ten healthy male subjects (age range, 19-27 years) were exercised at $65 \%$ of $\mathrm{VO}_{2}$ max at an environmental temperature of $32.06 \pm 0.02^{\circ} \mathrm{C}$ on which relative humidity of 